Published in final edited form as:

Small. 2013 August 26; 9(16): 2721-2720. doi:10.1002/smll.201202508.

\title{
Biodegradation of Single-Walled Carbon Nanotubes by Eosinophil Peroxidase
}

\author{
Fernando T. Andón, \\ Division of Molecular Toxicology, Institute of Environmental Medicine, Karolinska Institutet, \\ Nobels Väg 13, Stockholm, 17177, Sweden
}

\begin{abstract}
Alexandr A. Kapralov,
Department of Environmental and Occupational Health, University of Pittsburgh, 100 Technology, Drive, Pittsburgh, PA 15219, USA

\section{Naveena Yanamala,}

Pathology \& Physiology Research Branch, NIOSH, 1095 Willowdale Road, Morgantown, WV 26505, USA

\section{Weihong Feng,}

Department of Environmental and Occupational Health, University of Pittsburgh, 100 Technology, Drive, Pittsburgh, PA 15219, USA
\end{abstract}

\section{Arjang Baygan,}

Center for Infectious Medicine, Department of Medicine, Karolinska Institutet, Karolinska University Hospital, Stockholm, 17177, Sweden

\section{Benedict J. Chambers,}

Center for Infectious Medicine, Department of Medicine, Karolinska Institutet, Karolinska University Hospital, Stockholm, 17177, Sweden

\section{Kjell Hultenby,}

Clinical Research Center, Department of Laboratory Medicine, Karolinska Institutet, Karolinska University Hospital Huddinge, Stockholm, 14186, Sweden

Fei Ye,

Functional Materials Division, Department of Materials and Nanophysics, Royal Institute of Technology, Stockholm, 16440, Sweden

\section{Muhammet S. Toprak,}

Functional Materials Division, Department of Materials and Nanophysics, Royal Institute of Technology, Stockholm, 16440, Sweden

\footnotetext{
(C) 2013 Wiley-VCH Verlag GmbH \& Co. KGaA, Weinheim

Correspondence to: Bengt Fadeel, bengt . fadeel@ki . se; Valerian E. Kagan, kagan@pitt .edu.

Supporting Information

Supporting Information is available from the Wiley Online Library or from the author. It includes Supplementary Figures 1-3 and Supplementary Table 1.

Disclaimer: The findings and conclusions in this report are those of the authors and do not necessarily represent the views of the National Institute for Occupational Safety and Health.
} 
Birgit D. Brandner, Institute for Surface Chemistry, Stockholm, 11428, Sweden

Andrea Fornara, Institute for Surface Chemistry, Stockholm, 11428, Sweden

Judith Klein-Seetharaman, Department of Structural Biology, University of Pittsburgh School of Medicine, Pittsburgh, PA 15260, USA

Gregg P. Kotchey, Department of Chemistry, University of Pittsburgh, Pittsburgh, PA 15260, USA

Alexander Star, Department of Chemistry, University of Pittsburgh, Pittsburgh, PA 15260, USA

Anna A. Shvedova, Health Effects Laboratory Division, NIOSH, 1095 Willowdale Road, Morgantown, WV 26505, USA Department Pharmacology \& Physiology, West Virginia University, Morgantown, WV 26505, USA

Bengt Fadeel, and

Division of Molecular Toxicology, Institute of Environmental Medicine, Karolinska Institutet, Nobels Väg 13, Stockholm, 17177, Sweden

\author{
Valerian E. Kagan \\ Department of Environmental and Occupational Health, University of Pittsburgh, 100 Technology, \\ Drive, Pittsburgh, PA 15219, USA \\ Bengt Fadeel: bengt.fadeel@ki.se; Valerian E. Kagan: kagan@pitt.edu
}

\title{
Abstract
}

Eosinophil peroxidase (EPO) is one of the major oxidant-producing enzymes during inflammatory states in the human lung. The degradation of single-walled carbon nanotubes (SWCNTs) upon incubation with human EPO and $\mathrm{H}_{2} \mathrm{O}_{2}$ is reported. Biodegradation of SWCNTs is higher in the presence of $\mathrm{NaBr}$, but neither EPO alone nor $\mathrm{H}_{2} \mathrm{O}_{2}$ alone caused the degradation of nanotubes. Molecular modeling reveals two binding sites for SWCNTs on EPO, one located at the proximal side (same side as the catalytic site) and the other on the distal side of EPO. The oxidized groups on SWCNTs in both cases are stabilized by electrostatic interactions with positively charged residues. Biodegradation of SWCNTs can also be executed in an ex vivo culture system using primary murine eosinophils stimulated to undergo degranulation. Biodegradation is proven by a range of methods including transmission electron microscopy, UV-visible-NIR spectroscopy, Raman spectroscopy, and confocal Raman imaging. Thus, human EPO (in vitro) and ex vivo activated eosinophils mediate biodegradation of SWCNTs: an observation that is relevant to pulmonary responses to these materials.

\section{Introduction}

Carbon nanotubes (CNTs) consist of carbon atoms arranged in condensed aromatic rings, which in turn are organized in one (single-walled carbon nanotubes: SWCNTs) or more 
(multi-walled carbon nanotubes: MWCNTs) concentric graphene sheets rolled-up into cylinders. CNTs are among the most studied nanomaterials to date and are currently of interest for a variety of uses in technological as well as biomedical applications, including drug delivery devices and contrast agents in medical imaging. Paradoxically, the novel characteristics of nanomaterials that are essential for successful and innovative applications might also lead to negative health impacts. ${ }^{[1]}$ Cell culture studies indicate that SWCNTs may be cytotoxic, largely through the induction of oxidative stress. ${ }^{[2-4]}$ Mice exposed to CNTs by either aspiration or inhalation develop an early inflammatory response and oxidative stress culminating in the development of multifocal granulomatous pneumonia and interstitial fibrosis. ${ }^{[5-10]}$ Several studies have shown that both SWCNTs and MWCNTs promote allergic immune responses in mice with an infiltration of eosinophils in the lung. ${ }^{[9-11]}$ Moreover, an increase in blood and broncheoalveolar (BAL) eosinophil numbers was recently shown to be a consistent feature in mice exposed by pharyngeal aspiration to CNTs. ${ }^{[12]}$ In addition, eosinophilia is seen in response to parasitic infection, and it is a common feature in allergic and asthmatic conditions. Therefore, there is a need to understand the consequences of exposure to CNTs (and other nanomaterials) in individuals with pre-existing infection or allergic disease. ${ }^{[13]}$

Intraperitoneal injection of MWCNTs in mice has been reported to trigger inflammation and granuloma formation. ${ }^{[14,15]}$ Furthermore, MWCNTs have been shown to reach the subpleura in mice after a single inhalation exposure with attendant subpleural fibrosis. ${ }^{[16]}$ Needless to say, minimizing inhalation of CNTs during handling is prudent. Nevertheless, strategies to mitigate the adverse effects of CNTs are also needed. To this end, we and others have demonstrated in previous studies that CNTs can be biodegraded through natural enzymatic catalysis. ${ }^{[17-19]}$ Carboxylated SWCNTs incubated with horseradish peroxidase (HRP) and low concentrations of $\mathrm{H}_{2} \mathrm{O}_{2}$ over several weeks were thus found to undergo biodegradation. Incubation with ferric iron species including hemin or $\mathrm{FeCl}_{3}$ with $\mathrm{H}_{2} \mathrm{O}_{2}$ resulted in the degradation of both carboxylated and pristine SWCNTs, consistent with a homolytic cleavage of $\mathrm{H}_{2} \mathrm{O}_{2}$ and the formation of free radicals. These hydroxyl and hydroperoxyl radicals were able to oxidize both carboxylated and pristine SWCNTs, initiating their biodegradation. ${ }^{[20]}$ Additionally, we have demonstrated that hypochlorite and reactive radical intermediates of the human neutrophil enzyme myeloperoxidase (MPO) catalyze the biodegradation of SWCNTs in neutrophils and to a lesser degree in macrophages. ${ }^{[21]}$ SWCNTs were completely degraded in presence of MPO, hypochlorite and $\mathrm{H}_{2} \mathrm{O}_{2}$, and cellular uptake and MPO-driven degradation of immunoglobulin-coated SWCNTs, occurred in primary human neutrophils cultivated ex vivo. Macrophages were less proficient at biodegrading SWCNTs, in line with the fact that these cells express much lower amounts of MPO when compared to neutrophils. Importantly, SWCNTs that were fully biodegraded by MPO in vitro did not elicit the typical inflammatory and oxidative stress responses characteristic of CNTs after pharyngeal aspiration in mice. ${ }^{[21]}$ We also provided evidence for in vivo biodegradation of SWCNTs insofar as clearance of SWCNTs from the lungs of MPO-deficient mice was markedly less effective whereas the inflammatory/pro-fibrotic response was more robust as compared to wild-type mice. ${ }^{[22]}$ Collectively, these studies suggest new ways to control the biopersistence of CNTs through genetic or pharmacological manipulations. 
While neutrophil MPO is particularly important in mediating bacterial cell killing, eosinophil peroxidase (EPO) expressed in eosinophils is largely responsible for destroying invading parasites. ${ }^{[23]} \mathrm{EPO}$ is a heme-containing haloperoxidase with a $68 \%$ sequence identity to neutrophil MPO. EPO catalyzes the peroxidative oxidation of halides (such as bromide, chloride, and iodide) and pseudohalides (thiocyanate) present in the plasma together with hydrogen peroxide generated by dismutation of superoxide produced during the respiratory burst. This reaction leads to the formation of hypohalous acids, particularly hypobromous acid, under physiologic conditions. ${ }^{[24]}$ Eosinophils are robust producers of extracellular superoxide due to expression of high levels of the NADPH oxidase, an enzyme complex that generates superoxide ${ }^{[25]}$ and preferential assembly of the NADPH oxidase at the cell surface in these cells. ${ }^{[26]}$ Notably, EPO is one of the major oxidant generating enzymes present in the human lung, which are induced during inflammatory states. ${ }^{\left[{ }^{[2]}\right.}$ It has recently been described that CNTs induce acute pulmonary eosinophilia and release of EPO into inflammatory foci in the lungs of exposed mice. ${ }^{[28]}$ We reasoned that EPO released from eosinophils under physiologically relevant conditions could play an important role in the biodegradation of CNTs. Here we have addressed the ability of EPO to degrade SWCNTs. We have studied the effect of EPO in combination with $\mathrm{H}_{2} \mathrm{O}_{2}$ and $\mathrm{NaBr}$ to explore the role of peroxidase intermediates that can be produced in biofluids under physiologic conditions. Computer modeling was used to structurally characterize possible nanotube interaction sites with EPO. Additionally, the use of primary murine eosinophils generated from bone marrow progenitors allowed us to assess oxidative biodegradation of SWCNTs by exocytosed EPO under relevant ex vivo conditions. These studies are the first to demonstrate that eosinophils-key players of the innate immune system-have the capacity to degrade SWCNTs.

\section{Results and Discussion}

$\mathrm{EPO}$, like other peroxidases, predominantly catalyzes a two-electron redox reaction, using $\mathrm{H}_{2} \mathrm{O}_{2}$ to oxidize a halide to its corresponding hypohalous acids, and produce reactive radical intermediates. In order to study whether biodegradation of SWCNTs is induced by EPO in vitro, we added human EPO and $\mathrm{H}_{2} \mathrm{O}_{2}$ to suspensions of SWCNTs. We observed that the carbon nanotubes were degraded over time, and the SWCNTs suspension turned translucent after $96 \mathrm{~h}$ (Figure 1a). Neither hEPO alone nor $\mathrm{H}_{2} \mathrm{O}_{2}$ alone caused degradation of SWCNTs (data not shown).

EPO is a peroxidase unique to eosinophils that, in contrast to myeloperoxidase (MPO), preferentially oxidizes $\mathrm{Br}^{-}$to hypobromous acid (HOBr), rather than $\mathrm{Cl}^{-}$to hypochlorous acid $(\mathrm{HOCl})$ at physiologically relevant (i.e. serum) concentrations, where $\mathrm{Cl}^{-}$is in $>1000$ fold excess $\left(100 \mathrm{mM} \mathrm{Cl}^{-}, 20-100 \mu \mathrm{M} \mathrm{Br}^{-}\right) .{ }^{[29]}$ Both reactive intermediates of $\mathrm{EPO}$ and $\mathrm{HOBr}$ are formed when EPO is incubated with $\mathrm{H}_{2} \mathrm{O}_{2}$ in the presence of sodium bromide $(\mathrm{NaBr})$. At the same time only peroxidase reactive radical intermediates are generated in the absence of $\mathrm{NaBr}$. We found that the biodegradation of SWCNTs with $\mathrm{hEPO}$ and $\mathrm{H}_{2} \mathrm{O}_{2}$ was higher in the presence of $\mathrm{NaBr}$, suggesting that not only reactive radical intermediates of EPO but also generated $\mathrm{HOBr}$ was involved in the biodegradation process (Figure 1a, d). Another possible explanation could be that the EPO structure is stabilized in the presence of $\mathrm{NaBr}$ (as suggested by molecular modelling) retaining the peroxidase activity for longer 
time. We therefore assessed the activity of hEPO after its incubation in the presence of $\mathrm{H}_{2} \mathrm{O}_{2}$ and SWCNTs using Amplex Red. During the peroxidase cycle of EPO, a two electron oxidation of its ferric heme iron $\left(\mathrm{Fe}^{3+}\right)$ by $\mathrm{H}_{2} \mathrm{O}_{2}$ yields oxo-ferryl iron $\left(\mathrm{Fe}^{4+}=\mathrm{O}\right)$ and porphyrin $\pi$ cation radical. This primary reactive intermediate of the enzyme is subsequently converted to the ferric resting state in two sequential one-electron transfer steps by interaction with reducing substrates. ${ }^{[30]}$ Amplex Red is one of the prototypical substrates commonly used in measurements of peroxidase activity due to its oxidation to a highly fluorescent product, resorufin. A decrease in the peroxidase activity of hEPO was observed after 2 and $4 \mathrm{~h}$ of incubation that could be prevented by the addition of $\mathrm{NaBr}$ (Figure 1b). Our results show that $\mathrm{NaBr}$ not only protects the enzyme against time-dependent inactivation, but in fact activates the enzyme very significantly (Figure 1b). Thus, it is logical to suggest that this sustained high activity of the enzyme contributes to more effective biodegradation of carbon nanotubes in presence of $\mathrm{NaBr}$. We confirmed the degradation of CNTs by several complementary approaches. Using visible-near-infrared (vis-NIR) absorbance spectroscopy the typical vis-NIR spectra of CNTs was observed, showing the characteristic metallic band (M1) and the semiconducting (S2) transition band (Figure 1c). Then, after subtraction of scattering, we detected a decrease of absorbance in the region of the semiconducting transition band (S2) of SWCNTs that were co-incubated with $\mathrm{hEPO}$ and $\mathrm{H}_{2} \mathrm{O}_{2}$, and a higher degradation was seen when adding hEPO and $\mathrm{H}_{2} \mathrm{O}_{2}$ plus $\mathrm{NaBr}$ (Figure 1d). In addition, drastic changes in CNT morphology were demonstrated by TEM. CNTs incubated with $\mathrm{H}_{2} \mathrm{O}_{2}(100 \mu \mathrm{M})$ and $\mathrm{NaBr}(100 \mu \mathrm{M})$, which were added every 1 $\mathrm{h}$, and $5 \mu \mathrm{l}$ of hEPO was added every $12 \mathrm{~h}$. The characteristic fibrillar structure of intact CNTs was completely lost, and the bulk of the CNTs was no longer present after $120 \mathrm{~h}$ of incubation with the active enzyme. Only a few visual fields showed evidence of residual carbonaceous material (Figure 1e). These results are in agreement with our previous studies using HRP. ${ }^{[20]}$ Furthermore, Raman spectroscopy showed an increase of disorder-induced D-band at $\sim 1340 \mathrm{~cm}^{-1}$ and decrease of tangential-mode G-band at $\sim 1580 \mathrm{~cm}^{-1}$, suggesting that the graphene sidewall was oxidized (Figure 2). Because the D band characterizes the disorder-induced mode due to symmetry-lowering effects such as defects in $\mathrm{sp}^{2}$ hybridized carbon systems, the increase in the D to $\mathrm{G}$ band intensity ratio suggests an increase in defect sites introduced on CNTs. ${ }^{[31]}$

Molecular docking studies were performed using Auto-Dock Vina software to structurally characterize possible SWCNTs interaction sites on EPO (Figure 3). EPO-catalyzed biodegradation of SWCNTs may generate multiple oxidation products including carboxylated and hydroxylated moieties on the surface as well as a variety of oxygenated aliphatic and aromatic low molecular weight products: similar to those detected in our previous study for reactions with horseradish peroxidase and heme. ${ }^{[20]}$ In the same investigation, atomic force microscopy (AFM) studies of SWCNTs indicated that the most predominant species had a diameter of $1.3 \mathrm{~nm}$ and $(8,8)$ chirality. ${ }^{[20]}$ Further, the defects (carboxyl, hydroxyl groups) on SWCNTs were mostly localized to the ends and in some cases to the sidewalls of SWCNTs as described previously in ${ }^{[21]}$ thus suggesting that the SWCNT structures chosen for the current docking studies mimicked the actual SWCNT samples employed in the experimental studies. The docking of oxidized SWCNTs to the homology model of EPO indicated different binding sites on EPO (Figure 3). Two different 
types of oxidized SWCNTs were used for docking one modified at edges and the other in the middle of the carbon nanotubes, as noted above. In both cases, they were found to localize in common to two binding sites on EPO, one located at the proximal side (same side as the catalytic site) and the other on the distal side of EPO (Figure 3a). The oxidized groups on SWCNTs in both cases are stabilized by electrostatic interaction with positively charged residues (Figure 3c, d, Table S1, highlighted in bold). While the preference for each site in each case was not identical, the lowest energy conformation in both cases was located at binding site 1 (Table S1). The interaction of SWCNTs at this site is predicted to be stabilized by a set of residues involving Arg205, Leu206, Arg207, Asn208, Arg209, Thr210, Ala217, Gln220, Arg221, Pro231, Phe232, Asn234, and Leu253 (Figure 3 c, Table S1). Specifically, the oxidized groups on SWCNTs are stabilized by electrostatic interactions with positively charged residues, Arg205, Arg207 and Arg209 in binding site 1 and Arg94, and Arg99 in site 2. Further binding site 1 is located on the same side as catalytic site of EPO (Figure 3 a) and is also closer to the entrance of the catalytic site as compared to binding site 2 (Figure S2c). Together, these results indicate that the binding of oxidized SWCNTs at site 1 is a preferable site for biodegradation as compared to site 2 . In addition to this, the interaction at site 1 also overlaps with one of the bromide ion binding site observed in the crystal of MPO (PDBID:1D2V). This suggests that the protective effect of $\mathrm{NaBr}$ is due to the presence of a $\mathrm{Br}^{-}$ion binding site on EPO molecule at a similar site as binding site 1 (Figure S2). Binding of $\mathrm{Br}^{-}$could stabilize the structure of EPO and further allow for the effective degradation of SWCNTs that are bound in close proximity. In general, the halide ions require either water molecules (as a source of oxygen) or ferryl oxygen for the formation of hypohalous acids. The oxidized groups $\left({ }^{-} \mathrm{OOH},{ }^{-} \mathrm{OH}\right.$ groups) on SWCNTs bound in close proximity to the $\mathrm{Br}^{-}$binding site as predicted by docking studies may fulfill the requirement of oxygen source for the formation of $\mathrm{HOBr}$. The destabilization of the SWCNT structures upon extraction of oxygen from the oxidized groups itself and/or further oxidation of SWCNT by the subsequently formed $\mathrm{HOBr}$ may lead to the degradation of SWCNTs. Thus, these results are in line with the experimental data indicating that the presence of both radicals and $\mathrm{Br}^{-}$ions leads to efficient degradation of SWCNTs. Despite the excellent agreement between the modeling studies and experimental data, one has to be cautious in considering the molecular details of the predicted SWCNTs binding as the 3D structure of EPO plays a central role in determining the success of these docking calculations. Nevertheless, given that EPO shares an amino acid sequence identity of $68 \%$ with MPO the generated model of EPO using MPO as a structural template may be considered to be accurate given that target sequences with $>50 \%$ sequence identity to a known structure template often lead to the prediction of precise models. ${ }^{[32]}$

We also found that human EPO-dependent degradation of nanotubes was more efficient at acidic $\mathrm{pH}$, both in presence or absence of $\mathrm{NaBr}$ (data not shown). In (patho)physiological conditions, this could be relevant to extracellular acidosis that is commonly observed in inflammatory diseases. ${ }^{[33]}$ Indeed, during lung inflammation the microenvironment becomes acidic. Hence, the $\mathrm{pH}$ of exhaled breath condensate is mildly alkaline in control persons $(7.65 \pm 0.20)$ and acidic $(5.23 \pm 0.21)$ in patients with acute asthma. ${ }^{[34]}$ CNTs have been shown to promote allergic immune responses and induce acute pulmonary eosinophilia, recruiting eosinophils and inducing the release of EPO into the foci of pulmonary 
inflammation. ${ }^{[28]}$ In order to simulate the pathophysiologic conditions of eosinophilia induced by an eventual CNT exposure, we have used an ex vivo culture system (Figure 4a) which allowed us to generate large numbers of eosinophils at high purity (>85\%) from unselected mouse bone marrow progenitors (Figure $4 \mathrm{~b}$ ). Degranulation of these primary murine eosinophils with exocytosis of murine eosinophil peroxidase (mEPO) was triggered by cytochalasin B and PAF or its deacetylated metabolite lyso-PAF (Figure 4c). Plateletactivating factor (PAF [1-O-alkyl-2-acetylsn-glycero-3-phosphocholine]) is a phospholipid secretory mediator released from activated macrophages, mast cells, and basophils that promotes inflammation. It has recently been shown by Dyer et al. that PAF and lyso-PAF are able to promote dose-dependent degranulation responses in human eosinophils and bone marrow-derived eosinophils. ${ }^{[35]}$ The fungal metabolite, cytochalasin B, which disrupts microfilament formation and facilitates the release of granule proteins augments the degranulation of mouse eosinophil in response to PAF and lyso-PAF. ${ }^{[35]}$ Indeed, in the current ex vivo model, lyso-PAF $(6 \mu \mathrm{M})$ in combination with cytochalasin B $(5 \mu \mathrm{g} / \mathrm{mL})$ caused a significant release of $\mathrm{mEPO}$, of up to $\sim 35 \%$ of the total cellular content of the granule protein $\mathrm{mEPO}$, compared to the combination of PAF $(6 \mu \mathrm{M})$ and cytochalasin B (5 $\mu \mathrm{g} / \mathrm{mL}$ ) (19.2\%) (Figure 4c). Using this ex vivo model, we evaluated whether oxidative biodegradation of CNTs can be executed by primary murine eosinophils activated to release mEPO extracellularly. SWCNTs were exposed to activated eosinophils up to $48 \mathrm{~h}$. Since, according to our pilot studies, the hEPO activity decays after $5 \mathrm{~h}$ (data not shown), we restimulated degranulation and mEPO release by adding lyso-PAF and cytochalasin B every 6 $\mathrm{h}$. TEM images showed that the bulk of the nanotubes was no longer present after $48 \mathrm{~h}$ of incubation, only a few visual fields showed evidence of residual carbon nanotubes and carbonaceous material (Figure 5a, b). Furthermore, the vis-NIR absorbance spectra, normalized by subtraction of scattering, showed a decrease in the absorbance at $1075 \mathrm{~nm}$ (wavelength characteristic for the semiconducting transition band S2) of treated carbon nanotubes compared with carbon nanotubes alone (Figure 5c). These results were confirmed by Raman microscopy as the tangential-mode G-band decreased after incubation with activated eosinophils compared with CNTs alone (for representative spectra, see Figure 6a, $\mathrm{b}$ and see Figure $\mathrm{S} 3$ for average spectra obtained from the intensity maps described below). We also visualized the presence of degraded SWCNTs after incubation with activated eosinophils (i.e. cells in which exocytosis of $\mathrm{mEPO}$ is induced using the above mentioned secretagogues) by Raman spectral mapping. Using this technique we obtained intensity maps, based on the D-band intensity at $1340 \mathrm{~cm}^{-1}$ or G-band intensity at $1580 \mathrm{~cm}^{-1}$, characteristic of degraded or non-degraded CNTs, respectively. Mapping realized at 1580 $\mathrm{cm}^{-1}$ showed a decrease in the areas of high intensity (in yellow/white) in treated carbon nanotubes compared with carbon nanotubes alone (Figure 6c, d). Moreover, while we can hardly detect the peak at $1340 \mathrm{~cm}^{-1}$ in CNTs alone (Figure 6e), areas of high intensity in these spectral maps indicated the presence of degraded CNTs after incubation with activated eosinophils (Figure 6f). These results show for the first time, using an ex vivo culture system of primary murine eosinophils, key cells of the innate immune system, the ability of such cells to degrade single-walled carbon nanotubes (SWCNTs). Eosinophils activated to release $\mathrm{mEPO}$ extracellularly were thus able to degrade SWCNTs, and modifications in the structure of the nanomaterials were evidenced by a range of methods including transmission 
electron microscopy (TEM), visible-near-infrared (vis-NIR) spectroscopy and confocal Raman imaging.

\section{Conclusion}

In summary, we have demonstrated that human EPO (in vitro) and murine EPO from ex vivo activated eosinophils catalyses the oxidative biodegradation of SWCNTs. Our experimental results are supported by computer modelling of the interactions between EPO and SWCNTs. We previously reported that neutrophil myeloperoxidase (MPO) catalyzes SWCNT biodegradation. ${ }^{[21]}$ It is pertinent to note, however, that in the latter study, SWCNTs were pre-opsonized with immunoglobulins in order to achieve efficient internalization of CNTs by neutrophils. In the present study, opsonisation is apparently not required because the biodegradative enzyme (EPO) is exocytosed upon cellular activation. Taken together, this study expands the repertoire of innate immune cells that are competent to enzymatically digest CNTs. ${ }^{[36]}$ Importantly, acute pulmonary eosinophilia has been described in response to respiratory exposure of CNTs. The demonstration that eosinophil peroxidase, one of the major oxidant generating enzymes present in human lung during inflammatory states, is able to degrade SWCNTs is therefore relevant to pulmonary responses to these materials. In addition, eosinophils have an unusually robust NADPH oxidase system for generation of superoxide and $\mathrm{H}_{2} \mathrm{O}_{2},{ }^{[37]}$ which may contribute to their degradative capacity. It is noteworthy that while neutrophil MPO is particularly important in mediating bacterial cell killing, instead EPO from eosinophils is largely responsible for destroying invading parasites, ${ }^{[23]}$ some of which are larger than eosinophils themselves, hence necessitating extracellular degradation. In sum, these findings point towards the development of strategies for mitigating the adverse effects of CNTs.

\section{Experimental Section}

Detailed methods are provided in the Supporting Information. Briefly, we prepared carboxylated single-walled carbon nanotubes (SWCNTs) ${ }^{[21]}$ by oxidation for 40 min and used them throughout the study (Figure S1). Peroxidase activity in vitro was assessed by Amplex Red, and fluorescence was detected by employing a 'Fusion a' universal microplate analyzer. For the assessment of carbon nanotube degradation by eosinophil peroxidase obtained from human blood (hEPO) in vitro, $15 \mu \mathrm{g}$ of SWCNTs, per sample, were incubated with hEPO (concentration $0.5 \mathrm{mg} / \mathrm{mL}$ ) in $100 \mathrm{mM}$ phosphate buffer $\left(\mathrm{pH} 7.4\right.$ ) at $37{ }^{\circ} \mathrm{C} . \mathrm{H}_{2} \mathrm{O}_{2}$ $(100 \mu \mathrm{M})$ and $\mathrm{NaBr}(100 \mu \mathrm{M})$ were added every $1 \mathrm{~h}, 5 \mu \mathrm{L}$ of hEPO were added every $12 \mathrm{~h}$. We assessed degradation of SWCNTs visually by a steady progression of fading color intensity and turbidity. In addition, we utilized aliquots removed from the incubating bulk samples at different time points, and the biodegradation of SWCNTs was studied using transmission electron microscopy (TEM), ultraviolet-visiblenear-infrared absorption spectroscopy (UV-vis-NIR) and Raman spectroscopy. Computer modeling: As there is no structural information available in the case of eosinophil peroxidase (EPO), a threedimensional model of EPO was built by homology modeling approach using the MODELLER software. ${ }^{[38,39]}$ The crystal structure of human myeloperoxidase (MPO) (PDBID: 1MHL) was used as a template. The structures of carboxylated SWCNTs, modified at the edge and in the middle, ${ }^{[21]}$ were docked to the structural model of EPO 
using AutoDock Vina software, version 2.0. ${ }^{[40]}$ The docking was performed using the complete structure of EPO as a search space for performing docking. Cellular assays were performed using murine bone marrow derived eosinophils, which were generated as described previously by Dyer et al. ${ }^{[41]}$ Bone marrow cells were collected from the femurs and tibiae from $\mathrm{BALB} / \mathrm{c}$ mice, and cultured in medium containing stem cell factor (SCF) and FLT3 ligand during 4 days. Then, cells were moved to new flasks and maintained in fresh medium supplemented with IL-5. Cells displaying Siglec F+CD11b+ greater than 85\% were used for biodegradation experiments. Eosinophil purity was typically $85-95 \%$. Detection of murine eosinophil peroxidase ( $\mathrm{mEPO}$ ) released from eosinophils in response to challenge with PAF or lysoPAF was essentially as described by Adamko et al. ${ }^{[42]}$ Cells were collected by centrifugation and resuspended in RPMI 1640, without phenol red; the cells were eliminated by centrifugation, and EPO activity was measured in the supernatant. The assay was developed using O-phenylenediamine reagent. Incubation of SWCNTs and activated eosinophils was performed as follows: $20 \mu \mathrm{g}$ of nanotubes were exposed to 20 million of activated eosinophils in culture flasks during $48 \mathrm{~h}$ at $37^{\circ} \mathrm{C}$. Lyso-PAF $(6 \mu \mathrm{M})$ and cytochalasin B $(5 \mu \mathrm{g} / \mathrm{mL})$ were added every $6 \mathrm{~h}$ to stimulate eosinophil degranulation. The cell suspensions were further subjected to sonication for $1 \mathrm{~h}$ and washed with PBS in order to remove cellular components prior to assessment of CNT biodegradation. TEM, vis-NIR, and confocal Raman microscopy were used to evaluate CNT degradation by eosinophils.

\section{Supplementary Material}

Refer to Web version on PubMed Central for supplementary material.

\section{Acknowledgements}

F. T. Andón and A. A. Kapralov contributed equally to this work. The authors are supported by the European Commission (FP7-MARINA; grant agreement 263215), the Swedish Research Council for Environment, Agricultural Sciences and Spatial Planning (FORMAS), National Institute for Occupational Safety and Health (NIOSH) OH008282, 3927ZJQP and 3927ZHF, National Institutes of Health NIEHS R01ES019304, HL70755, HL094488, U19AI068021, National Occupational Research Agenda NORA OHELD015, 927000Y, 927Z1LU, Nanotechnology Research Center (NTRC) 927ZJHF, National Science Foundation (NSF) CAREER 0449117 and Air Force Office of Scientific Research (AFOSR) FA9550-09-1-0478. GPK acknowledges support from the EPA STAR Graduate Fellowship FP-91713801.

\section{References}

1. Shvedova AA, Pietroiusti A, Fadeel B, Kagan VE. Toxicol. Appl. Pharmacol. 2012; 261:121-133. [PubMed: 22513272]

2. Jia G, Wang H, Yan L, Wang X, Pei R, Yan T, Zhao Y, Guo X. Environ. Sci. Technol. 2005; 39:1378-1383. [PubMed: 15787380]

3. Kisin ER, Murray AR, Keane MJ, Shi X-C, Schwegler-Berry D, Gorelik O, Arepalli S, Castranova V, Wallace WE, Kagan VE, Shvedova AA. J. Toxicol. Environ. Health Part A. 2007; 70:20712079. [PubMed: 18049996]

4. Kagan VE, Tyurina YY, Tyurin VA, Konduru NV, Potapovich AI, Osipov AN, Kisin ER, Schwegler-Berry D, Mercer R, Castranova V, Shvedova AA. Toxicol. Lett. 2006; 165:88-100. [PubMed: 16527436]

5. Shvedova AA, Kisin ER, Mercer R, Murray AR, Johnson VJ, Potapovich AI, Tyurina YY, Gorelik O, Arepalli S, Schwegler-Berry D, Hubbs AF, Antonini J, Evans DE, Ku B-K, Ramsey D, Maynard A, Kagan VE, Castranova V, Baron P. Am. J. Physiol. Lung Cell Mol. Physiol. 2005; 289:L698L708. [PubMed: 15951334] 
6. Shvedova AA, Kisin E, Murray AR, Johnson VJ, Gorelik O, Arepalli S, Hubbs AF, Mercer RR, Keohavong P, Sussman N, Jin J, Yin J, Stone S, Chen BT, Deye G, Maynard A, Castranova V, Baron PA, Kagan VE. Am. J. Physiol. Lung Cell Mol. Physiol. 2008; 295:L552-L565. [PubMed: 18658273]

7. Muller J, Huaux F, Moreau N, Misson P, Heilier J-F, Delos M, Arras M, Fonseca A, Nagy JB, Lison D. Toxicol. Appl. Pharmacol. 2005; 207:221-231. [PubMed: 16129115]

8. Teeguarden JG, Webb-Robertson B-J, Waters KM, Murray AR, Kisin ER, Varnum SM, Jacobs JM, Pounds JG, Zanger RC, Shvedova AA. Toxicol. Sci. 2011; 120:123-135. [PubMed: 21135415]

9. Inoue K, Koike E, Yanagisawa R, Hirano S, Nishikawa M, Takano H. Toxicol. Appl. Pharmacol. 2009; 237:306-316. [PubMed: 19371758]

10. Nygaard UC, Hansen JS, Samuelsen M, Alberg T, Marioara CD, Løvik M. Toxicol. Sci. 2009; 109:113-123. [PubMed: 19293371]

11. Inoue K-I, Yanagisawa R, Koike E, Nishikawa M, Takano H. Free Radic. Biol. Med. 2010; 48:924-934. [PubMed: 20093178]

12. Erdely A, Liston A, Salmen-Muniz R, Hulderman T, Young S-H, Zeidler-Erdely PC, Castranova V, Simeonova PP. J. Occup. Environ. Med. 2011; 53:S80-S86. [PubMed: 21654424]

13. Shvedova AA, Fabisiak JP, Kisin ER, Murray AR, Roberts JR, Tyurina YY, Antonini JM, Feng WH, Kommineni C, Reynolds J, Barchowsky A, Castranova V, Kagan VE. Am. J. Respir. Cell Mol. Biol. 2008; 38:579-590. [PubMed: 18096873]

14. Poland CA, Duffin R, Kinloch I, Maynard A, Wallace WAH, Seaton A, Stone V, Brown S, Macnee W, Donaldson K. Nat. Nanotechnol. 2008; 3:423-428. [PubMed: 18654567]

15. Takagi A, Hirose A, Nishimura T, Fukumori N, Ogata A, Ohashi N, Kitajima S, Kanno J. J. Toxicol. Sci. 2008; 33:105-116. [PubMed: 18303189]

16. Ryman-Rasmussen JP, Cesta MF, Brody AR, Shipley-Phillips JK, Everitt JI, Tewksbury EW, Moss OR, Wong BA, Dodd DE, Andersen ME, Bonner JC. Nat. Nanotechnol. 2009; 4:747-751. [PubMed: 19893520]

17. Allen BL, Kichambare PD, Gou P, Vlasova II, Kapralov AA, Konduru N, Kagan VE, Star A. Nano Lett. 2008; 8:3899-3903. [PubMed: 18954125]

18. Vlasova II, Sokolov AV, Chekanov AV, Kostevich VA, Vasil'ev VB. Bioorg. Khim. 2011; 37:510-521. [PubMed: 22096994]

19. Russier J, Ménard-Moyon C, Venturelli E, Gravel E, Marcolongo G, Meneghetti M, Doris E, Bianco A. Nanoscale. 2011; 3:893-896. [PubMed: 21116547]

20. Allen BL, Kotchey GP, Chen Y, Yanamala NVK, Klein-Seetharaman J, Kagan VE, Star A. J. Am. Chem. Soc. 2009; 131:17194-17205. [PubMed: 19891488]

21. Kagan VE, Konduru NV, Feng W, Allen BL, Conroy J, Volkov Y, Vlasova II, Belikova NA, Yanamala N, Kapralov A, Tyurina YY, Shi J, Kisin ER, Murray AR, Franks J, Stolz D, Gou P, Klein-Seetharaman J, Fadeel B, Star A, Shvedova AA. Nat. Nanotechnol. 2010; 5:354-359. [PubMed: 20364135]

22. Shvedova AA, Kapralov AA, Feng WH, Kisin ER, Murray AR, Mercer RR, St Croix CM, Lang MA, Watkins SC, Konduru NV, Allen BL, Conroy J, Kotchey GP, Mohamed BM, Meade AD, Volkov Y, Star A, Fadeel B, Kagan VE. PLoS ONE. 2012; 7:e30923. [PubMed: 22479306]

23. Davies MJ, Hawkins CL, Pattison DI, Rees MD. Antioxid. Redox Signal. 2008; 10:1199-1234. [PubMed: 18331199]

24. Hogan SP, Rosenberg HF, Moqbel R, Phipps S, Foster PS, Lacy P, Kay AB, Rothenberg ME. Clin. Exp. Allergy. 2008; 38:709-750. [PubMed: 18384431]

25. Someya A, Nishijima K, Nunoi H, Irie S, Nagaoka I. Arch. Biochem. Biophys. 1997; 345:207213. [PubMed: 9308891]

26. Lacy P, Abdel-Latif D, Steward M, Musat-Marcu S, Man SFP, Moqbel R. J. Immunol. 2003; 170:2670-2679. [PubMed: 12594296]

27. Kinnula VL. Curr. Drug Targets Inflamm. Allergy. 2005; 4:465-470. [PubMed: 16101523]

28. Girtsman TA, Beamer CA, Wu N, Buford M, Holian A. Nanotoxicology. 2012

29. Slungaard A, Mahoney JR Jr. J. Exp. Med. 1991; 173:117-126. [PubMed: 1985118] 
30. Furtmuller PG, Zederbauer M, Jantschko W, Helm J, Bogner M, Jakopitsch C, Obinger C. Arch. Biochem. Biophys. 2006; 445:199-213. [PubMed: 16288970]

31. Zhao Y, Allen BL, Star A. J. Phys. Chem. A. 2011; 115:9536-9544. [PubMed: 21348486]

32. Pieper U, Eswar N, Stuart AC, Ilyin VA, Sali A. Nucleic Acids Res. 2002; 30:255-259. [PubMed: 11752309]

33. Kottyan LC, Collier AR, Cao KH, Niese KA, Hedgebeth M, Radu CG, Witte ON, Khurana Hershey GK, Rothenberg ME, Zimmermann N. Blood. 2009; 114:2774-2782. [PubMed: 19641187]

34. Hunt JF, Fang K, Malik R, Snyder A, Malhotra N, Platts-Mills TA, Gaston B. Am. J. Respir. Crit. Care Med. 2000; 161:694-699. [PubMed: 10712309]

35. Dyer KD, Percopo CM, Xie Z, Yang Z, Kim JD, Davoine F, Lacy P, Druey KM, Moqbel R, Rosenberg HF. J. Immunol. 2010; 184:6327-6334. [PubMed: 20421642]

36. Kotchey GP, Hasan SA, Kapralov AA, Ha SH, Kim K, Shvedova AA, Kagan VE, Star A. Acc. Chem. Res. 2012; 45:1770-1781. [PubMed: 22824066]

37. DeChatelet LR, Shirley PS, McPhail LC, Huntley CC, Muss HB, Bass DA. Blood. 1977; 50:525535. [PubMed: 884325]

38. Sali A, Potterton L, Yuan F, van Vlijmen H, Karplus M. Proteins. 1995; 23:318-326. [PubMed: 8710825]

39. Martí-Renom MA, Stuart AC, Fiser A, Sánchez R, Melo F, Sali A. Annu. Rev. Biophys. Biomol. Struct. 2000; 29:291-325. [PubMed: 10940251]

40. Trott O, Olson AJ. J. Comput. Chem. 2010; 31:455-461. [PubMed: 19499576]

41. Dyer KD, Moser JM, Czapiga M, Siegel SJ, Percopo CM, Rosenberg HF. J. Immunol. 2008; 181:4004-4009. [PubMed: 18768855]

42. Adamko DJ, Wu Y, Gleich GJ, Lacy P, Moqbel R. J. Immunol. Methods. 2004; 291:101-108. [PubMed: 15345309] 


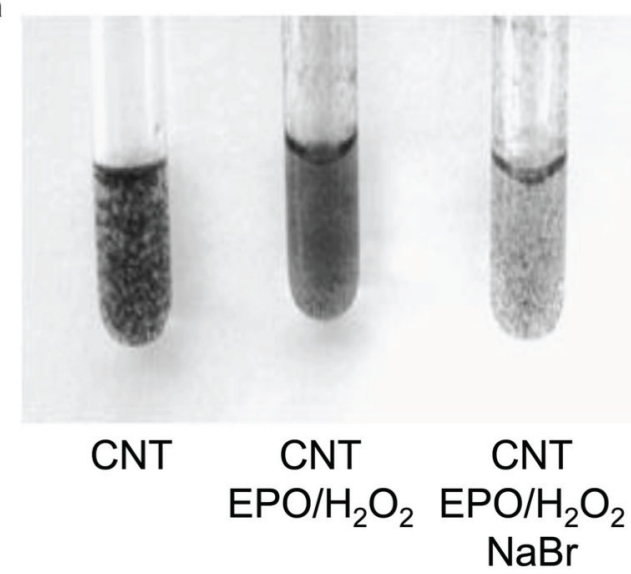

C

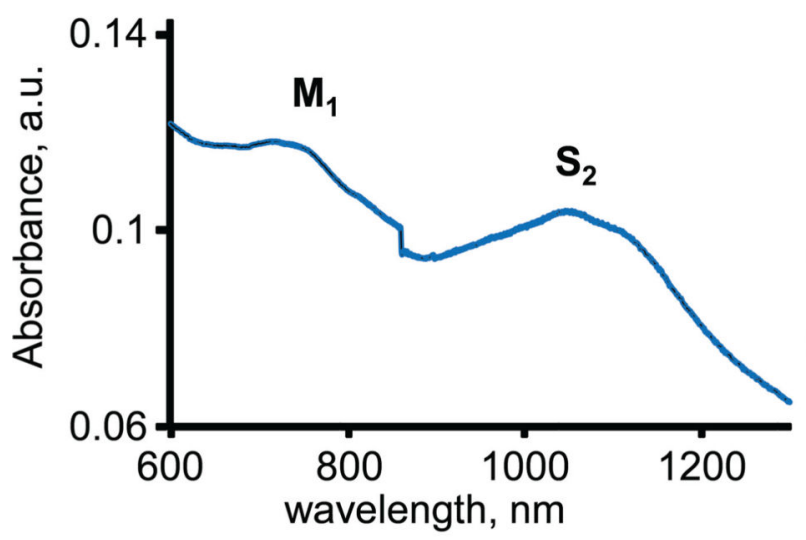

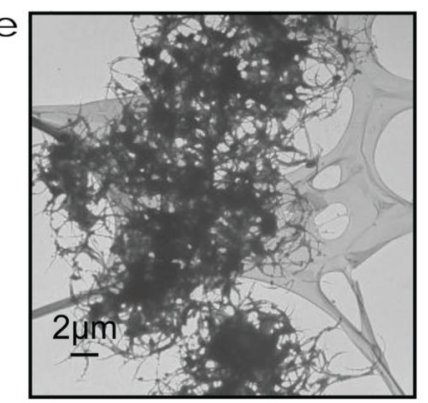

$\mathrm{Oh}$

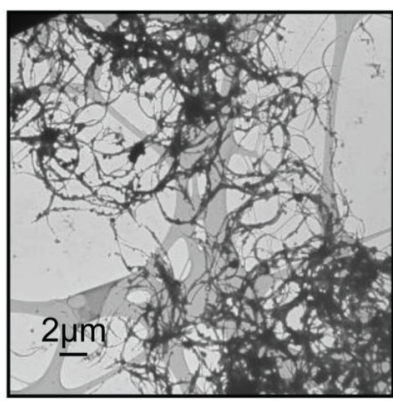

$48 \mathrm{~h}$

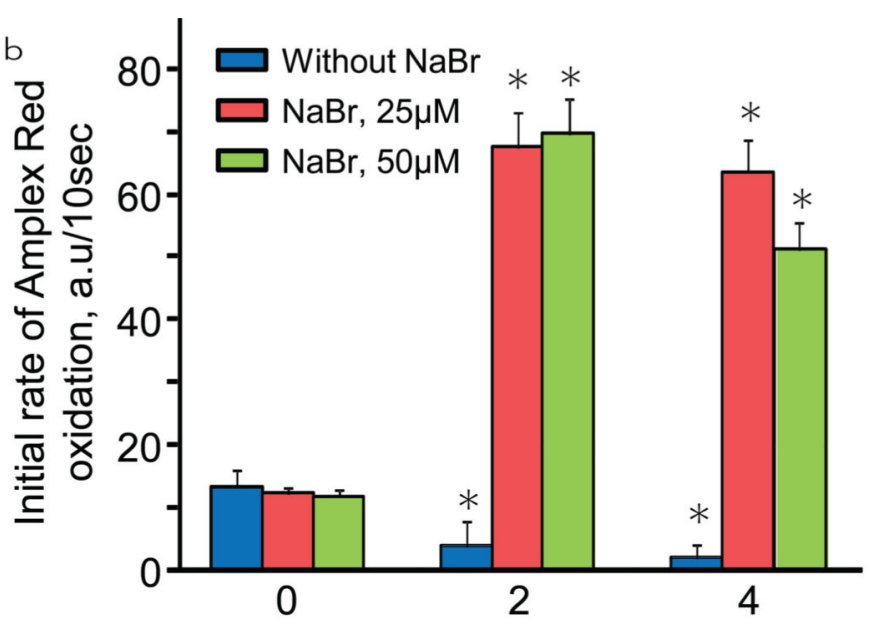

Time, hours

d

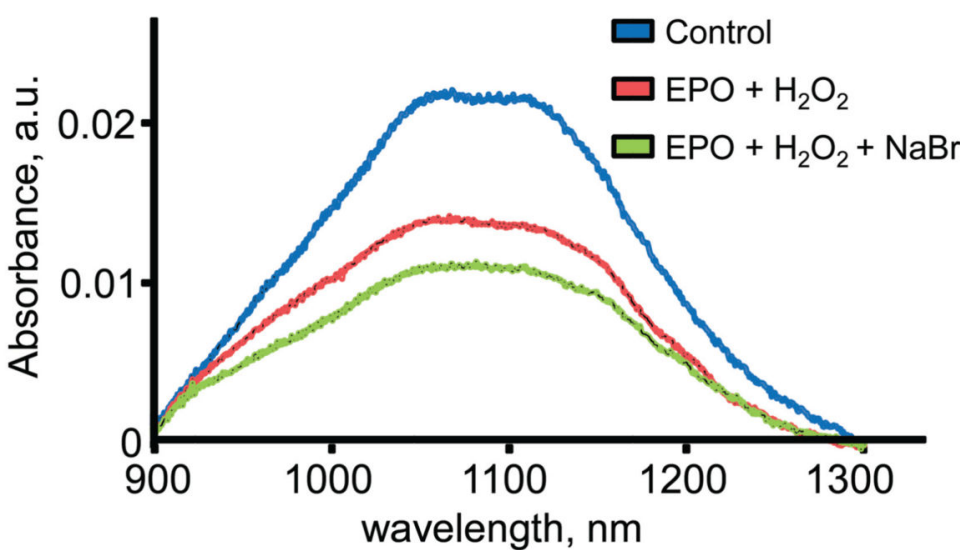

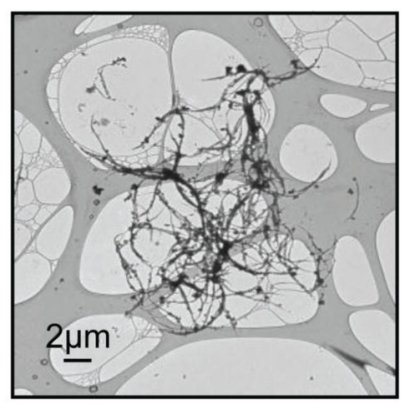

$72 \mathrm{~h}$

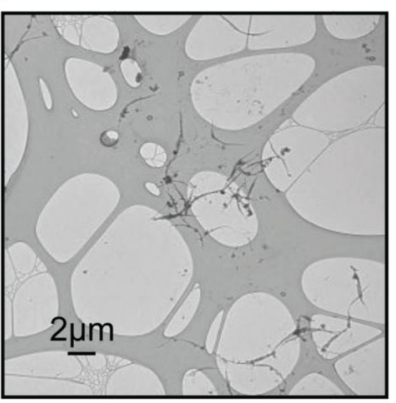

$120 \mathrm{~h}$

Figure 1.

EPO-mediated degradation of carbon nanotubes. Visual evidence, ultraviolet-visible-nearinfrared absorption spectroscopy and transmission electron microscopy (TEM) evaluation of in vitro degradation of SWCNTs. SWCNTs (15 $\mu$ g per sample) were incubated with hEPO in $100 \mathrm{mM}$ phosphate buffer $(\mathrm{pH} 7.4)$ at $37^{\circ} \mathrm{C} . \mathrm{H}_{2} \mathrm{O}_{2}(100 \mu \mathrm{M})$ and $\mathrm{NaBr}(100 \mu \mathrm{M})$ were added every $1 \mathrm{~h}, 5 \mu \mathrm{L}$ of hEPO was added every $12 \mathrm{~h}$. (a) CNT suspensions treated as indicated are shown after 96 h. (b) Assessment of peroxidase activity with Amplex Red showed that addition of $\mathrm{NaBr}$ prevents the loss of hEPO peroxidase activity after its incubation in the presence of $\mathrm{H}_{2} \mathrm{O}_{2}$ and CNTs, ${ }^{*} \mathrm{p}<0.01$. (c, d) UV-vis-NIR spectra 
showing loss of S2 band as the SWCNTs are degraded in the presence of hEPO; (c) typical spectra of CNTs, and (d) absorbance in the region of S2 band normalized by subtraction of scattering. (e) TEM analyses, tracking the biodegradation of SWCNTs over time. 

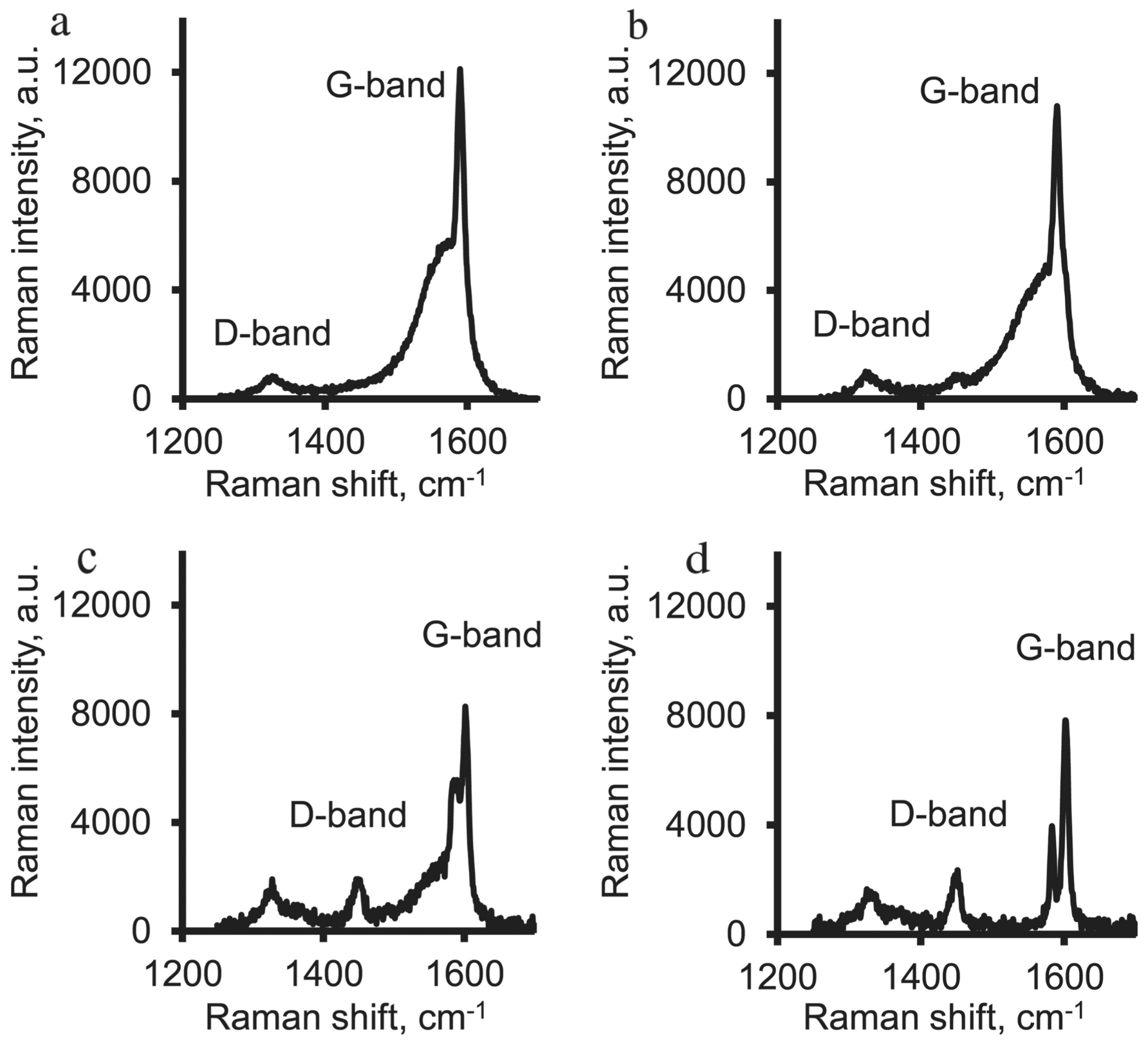

Figure 2.

Raman spectroscopy evaluation of human EPO-mediated degradation of SWCNTs in vitro. Raman spectra (excitation, $633 \mathrm{~nm}$ ) of nanotubes incubated with hEPO during $0 \mathrm{~h}$ (a), $48 \mathrm{~h}$ (b), $72 \mathrm{~h} \mathrm{(c)} \mathrm{and} 120 \mathrm{~h}$ (d), showing loss of the characteristic G-band, followed by appearance of the D-band over time. The conditions of incubation of hEPO and SWCNTs are as described in the legend to Figure 1. 
a

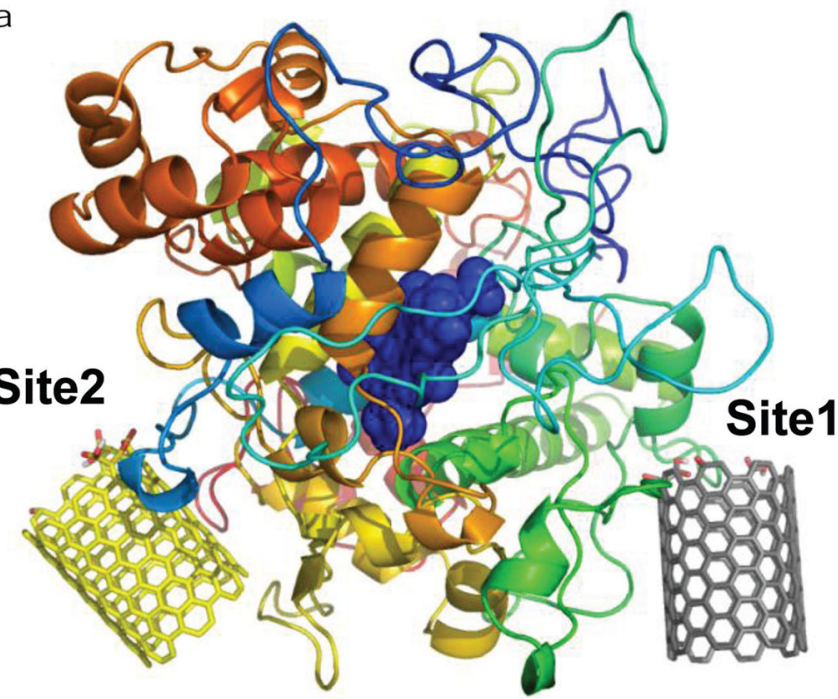

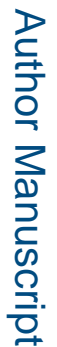

Figure 3. terminus in (a) and (b). b

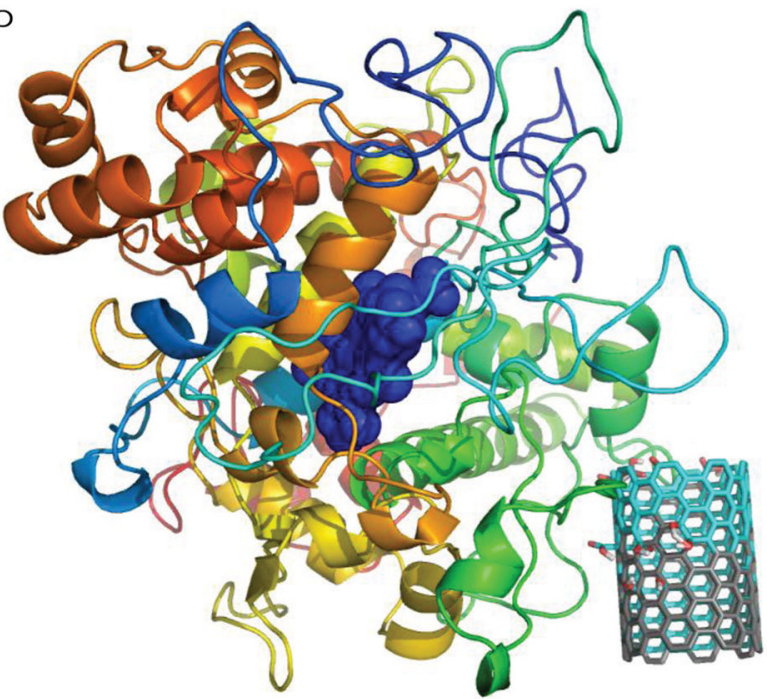

d

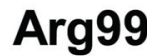

Arg94

$\operatorname{Arg} 209$

Thr210

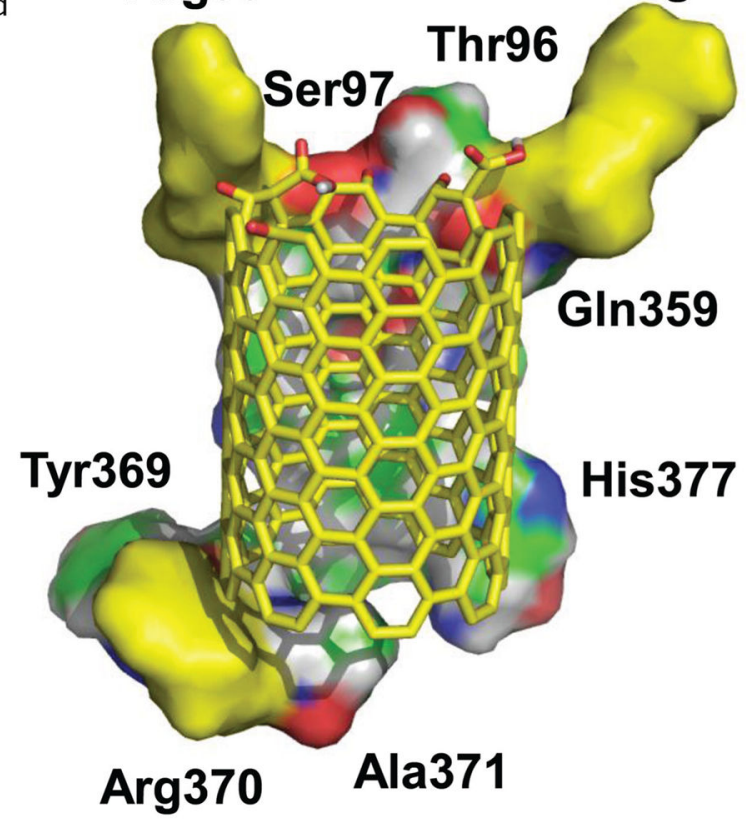

Molecular modelling demonstrating possible SWCNTs interaction sites on EPO. (a) The two predicted interaction sites, Site 1 and Site 2 of oxidized SWCNTs modified at the edge. The oxidized SWCNTs corresponding to Site 1 and Site 2 are rendered as sticks and colored in grey and yellow, respectively. (b) An overlay of the possible interaction Site 1 of SWCNTs oxidized at the edge (colored in grey) and in the middle (colored in cyan). The residues that are in close proximity (with in $4 \AA$ ), stabilizing the binding sites (c) Site 1 and (d) Site 2. Positively charged residues (arginines) that are predicted to stabilize the oxidized groups on SWCNTs are colored in yellow. The structure of EPO is colored in rainbow from $\mathrm{N}$ to $\mathrm{C}$ 


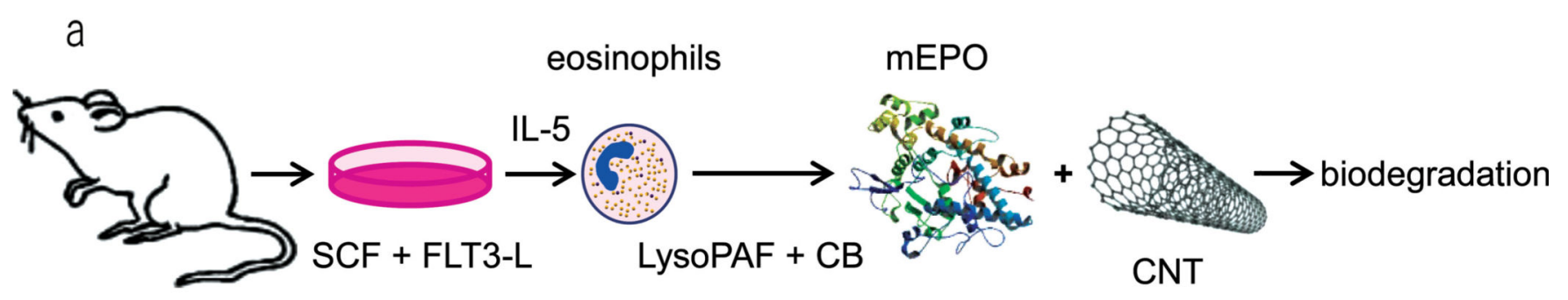

bone marrow cells
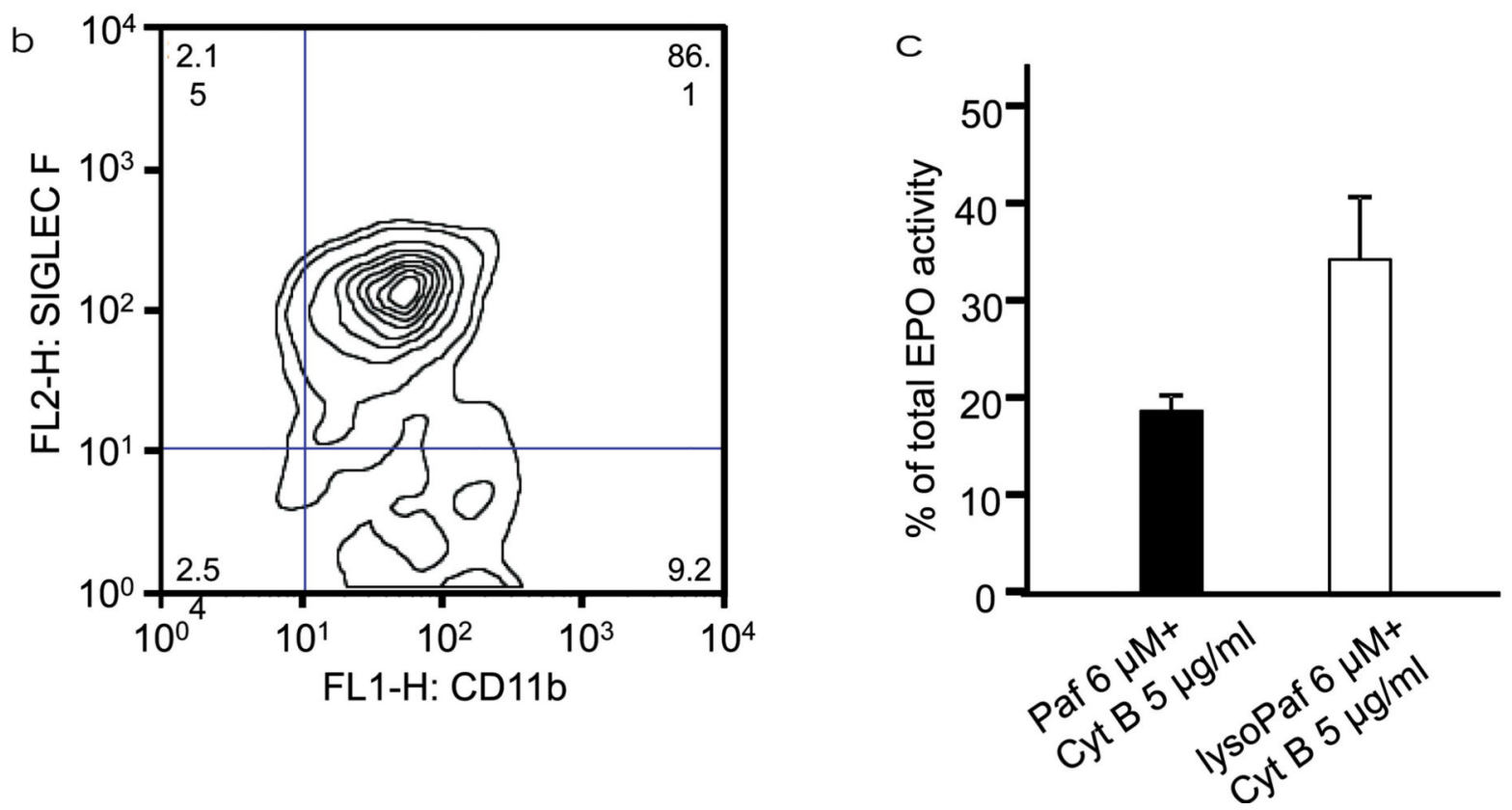

Figure 4.

Generation of murine eosinophils and release of EPO following activation. (a) Bone marrow cells were collected from the femurs and tibiae from BALB/c mice, and cultured in medium containing stem cell factor (SCF) and FLT3 ligand during 4 days. Then, cells were moved to new flasks and maintained in fresh medium supplemented with IL-5. Finally, the cells were stimulated with lyso-PAF and cytochalasin B and incubated with SWCNTs. (b) Mature eosinophils express the integrin chain CD11 and the cell surface antigen, Siglec-F. These proteins were detected by flow cytometry using Siglec F-PE conjugated and CD11b-FITC conjugated antibodies. Results from a typical experiment are shown. Eosinophils of $>85 \%$ purity were used for all subsequent biodegradation studies. (c) Eosinophils degranulate in response to challenge with cytochalasin B and PAF or lyso-PAF. Lyso-PAF $(6 \mu \mathrm{M})$ in combination with cytochalasin B $(5 \mu \mathrm{g} / \mathrm{ml})$ caused a large release of mEPO compared to the combination of PAF $(6 \mu \mathrm{M})$ and cytochalasin B $(5 \mu \mathrm{g} / \mathrm{ml})$. Data are reported as the percentage of total EPO[(absorbance of stimulated sample - no treatment $) \times 100 /$ total EPO from SDS - lysed cells]. Data are presented as mean \pm SD. 


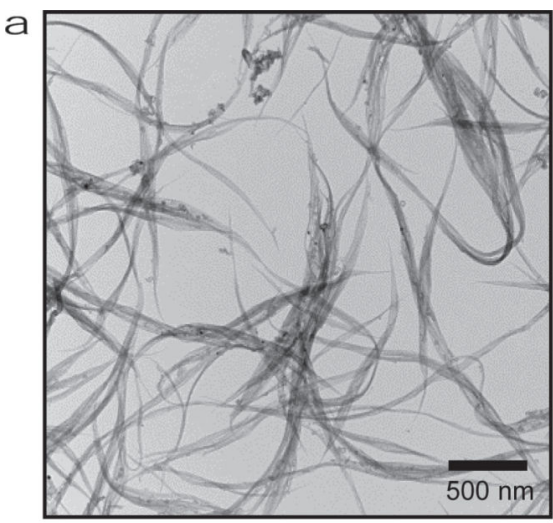

CNT

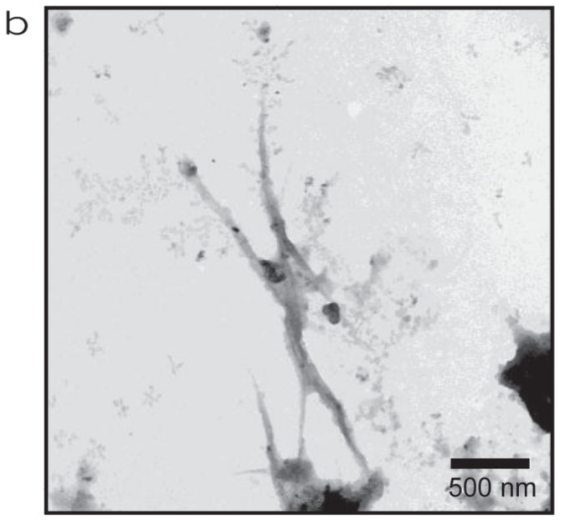

CNT/Eosinophils

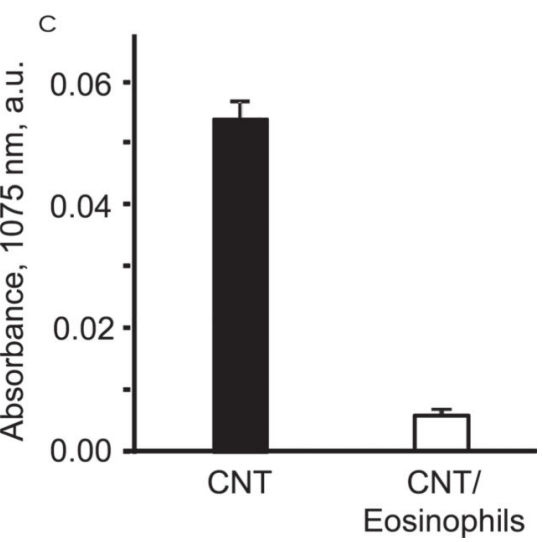

Figure 5.

Biodegradation of SWCNTs by primary murine eosinophils. (a, b) TEM images of different SWCNT suspensions alone (a) and after incubation during $48 \mathrm{~h}$ with activated eosinophils (b), where one can only detect a few residual SWCNTs, carbonaceous material and some cellular debris. (c) Vis-NIR spectra showing loss of absorbance at $1075 \mathrm{~nm}$ (S2 band characteristic of carbon nanotubes) normalized by subtraction of scattering, as carbon nanotubes are degraded after $48 \mathrm{~h}$ of incubation with activated eosinophils. Cells were activated as described in the legend to Figure 4. 
a

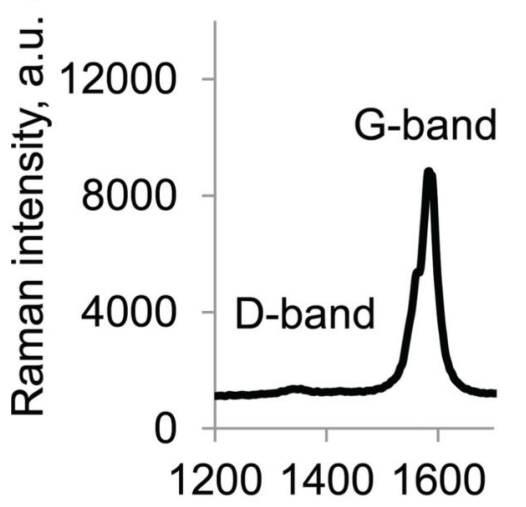

Raman shift, $\mathrm{cm}^{-1}$

C

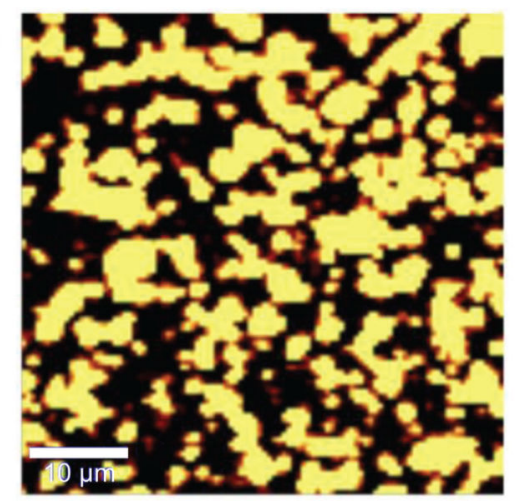

CNT

e

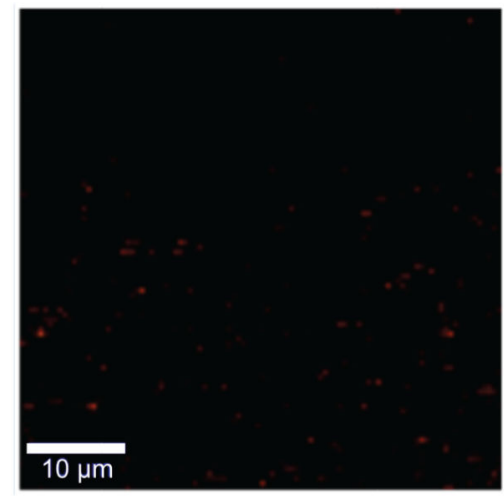

CNT b

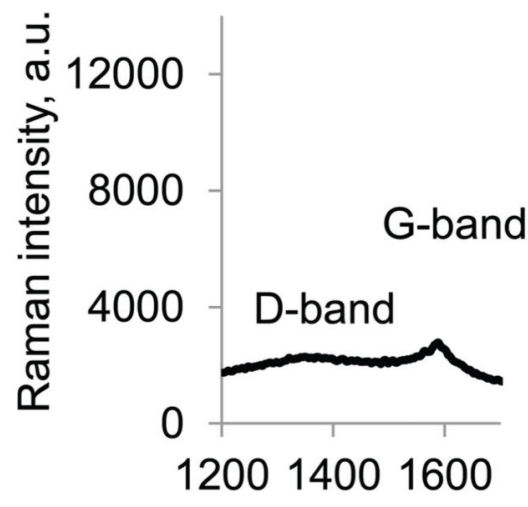

Raman shift, $\mathrm{cm}^{-1}$

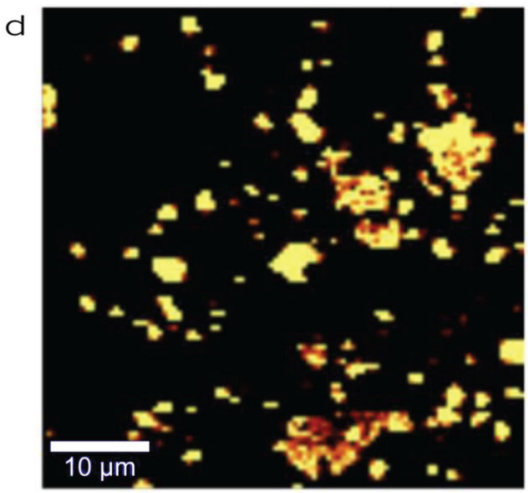

CNT/Eosinophils

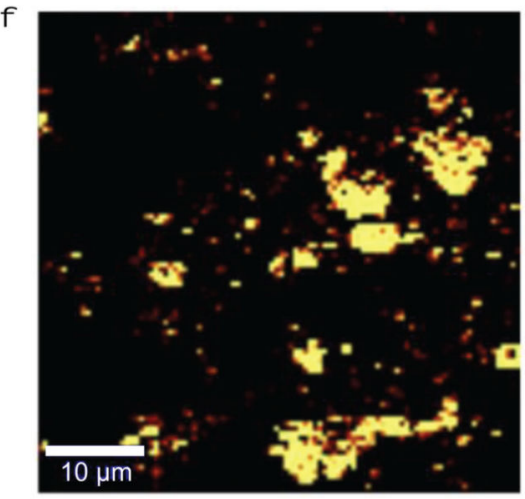

CNT/Eosinophils

Figure 6.

Biodegradation of CNTs assessed by Raman spectral mapping. Cells were activated as described in the legend to Figure 4 and the samples were evaluated after $48 \mathrm{~h}$ of incubation with or without cells. (a, b) Raman spectra of ethanol-dried CNTs with their corresponding G- and D-bands recorded from (a) non-eosinophil incubated and (b) eosinophil incubated nanotubes. (c-f) Confocal Raman microscopy showing intensity maps of G-band (indicative 
of non-degraded carbon nanotubes) recorded at $1580 \mathrm{~cm}^{-1}(\mathrm{c}, \mathrm{d})$ or D-band (indicative of degraded CNTs) at $1340 \mathrm{~cm}^{-1}(\mathrm{e}, \mathrm{f})$. 